\title{
Endoscopic resection of gastric lipoma with a hybrid technique of unroofing and loop ligation
}
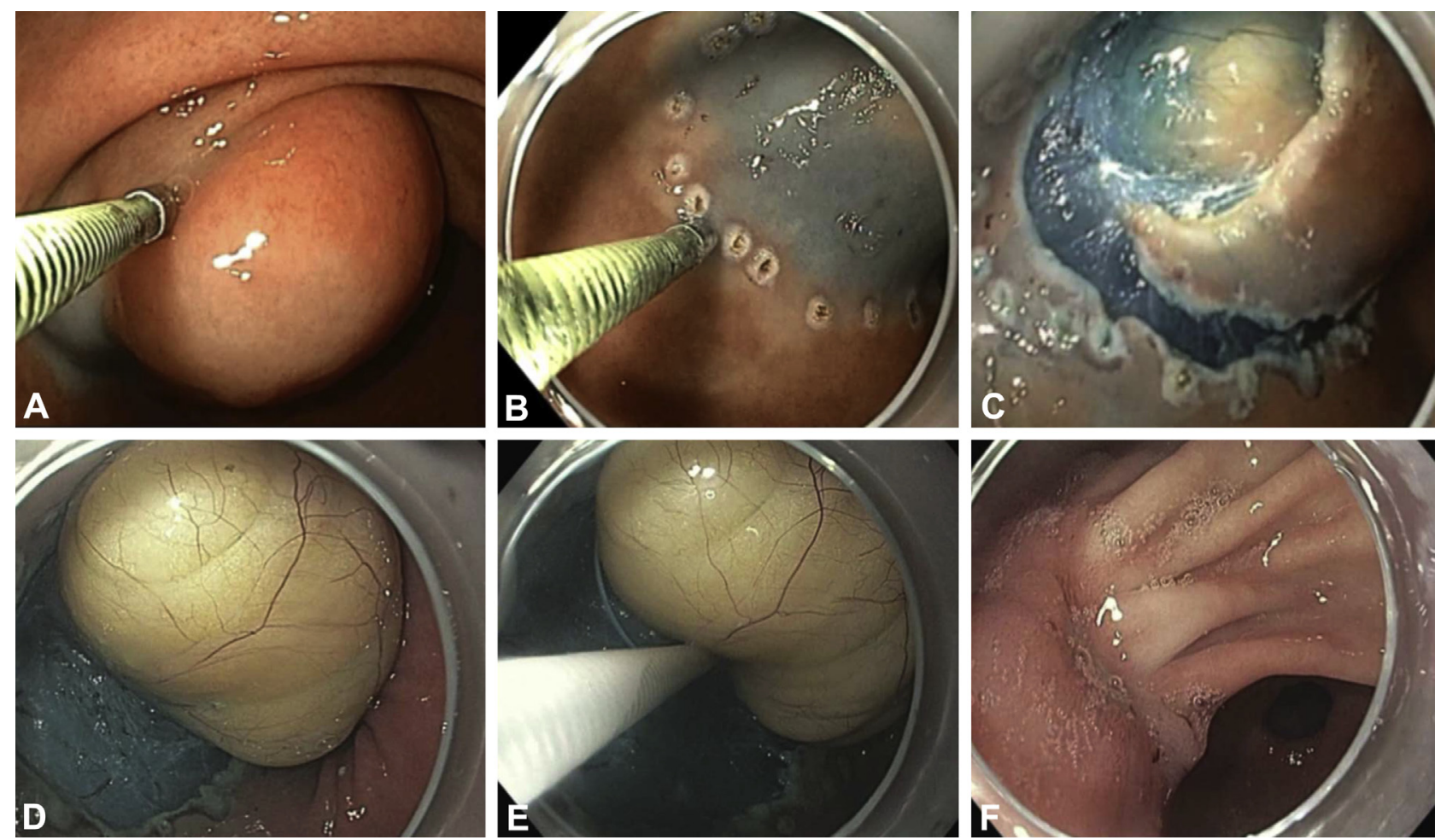

Figure 1. Initial injection of gastric lipoma (A), followed by marking with coagulation to guide the dissection $(\mathbf{B})$, unroofing of the mucosa $(\mathbf{C})$, exposure of the lipoma (D), placement of snare at base of the lesion $(\mathbf{E})$, and well-healed scar on follow-up endoscopy $(\mathbf{F})$.

A 53-year-old woman presented with symptoms of nausea and vomiting. CT demonstrated a wellcircumscribed 4-cm submucosal mass of fatty density. EUS revealed a homogeneous, hyperechoic, round mass in the submucosal layer of the gastric antrum consistent with a lipoma causing gastric outlet obstruction. Endoscopic resection was attempted, starting with lifting of the mucosal layer by the injection of diluted epinephrine mixed with methylene blue and hydroxyethyl starch (Video 1, available online at www. VideoGIE.org). A partial circumferential incision was then performed, followed by piecemeal unroofing of the overlying mucosa with a 33-mm snare. An endoscopic loop device was then inserted and opened beyond the size of the mass, followed by careful closure of the loop at the base of the lipoma. This ligation was performed to cut off the lipoma's blood supply leading to the lesion to slough off the mucosa once ischemic injury had taken place. The procedure lasted for 60 minutes. The patient reported mild abdominal pain after the procedure, which resolved of itself. Repeated endoscopy 4 weeks later showed no residual lipomatous tissue, and the patient's symptoms of gastric outlet obstruction had completely resolved (Fig. 1).

This case demonstrates the feasibility and effectiveness of a hybrid technique of unroofing and ligation in the management of a large gastric lipoma causing gastric outlet obstruction. Possible advantages associated with this technique include a relatively short procedure time (especially when compared with endoscopic submucosal dissection) and the ability to achieve 
complete resection with minimal risk for viscus perforation.

\section{DISCLOSURE}

Dr Khashab is a consultant for Boston Scientific and Olympus America and is the recipient of research support from Cook Medical. All other authors disclosed no financial relationships relevant to this publication.
Amol Agarwal, MD, Yen-I Chen, MD, Majidah Bukhari, MD, Olaya I. Brewer Gutierrez, MD, Mouen A. Khashab, MD, Department of Medicine, Division of Gastroenterology and Hepatology, The Johns Hopkins Medical Institutions, Baltimore, Maryland, USA

Copyright (c) 2017 American Society for Gastrointestinal Endoscopy. Published by Elsevier Inc. This is an open access article under the CC BY-NC-ND license (http://creativecommons.org/licenses/by-nc-nd/4.0/).

http://dx.doi.org/10.1016/j.vgie.2017.03.014 